\title{
O ENSINO DE FILOSOFIA NO BRASIL: UM BREVE OLHAR SOBRE ALGUMAS DAS PRINCIPAIS TENDÊNCIAS NO DEBATE ENTRE OS ANOS DE 1934 A 2008
}

\author{
Rodrigo Pelloso Gelamo*
}

\begin{abstract}
RESUMO
O propósito desse artigo é compreender o modo como o ensino da Filosofia é pensado na atualidade brasileira, a maneira por meio do qual o pensamento sobre esse ensino tem se constituído no espaço acadêmico das pesquisas sobre o assunto e as questões que são debatidas pelos pesquisadores dessa área. Para isso, apresentaremos um olhar sobre algumas tendências no debate que foi realizado no Brasil, com o objetivo de apontar alguns dos principais paradigmas que nortearam as diferentes abordagens sobre o ensino da Filosofia. Concordamos que esse recorte pode não representar o todo da discussão sobre o assunto, mas, de certo modo, pode servir de índice para entendermos o que foi feito nesse debate.

PALAVRAS-CHAVE: Ensino da Filosofia. Pensamento brasileiro. Educação.

ABSTRACT

The aim of this article is to understand the way how the teaching of philosophy has been thought in Brazil at the present time, the manner in which the reflection about this teaching has been constituted in the academic researches about the subject as well as the matters that have been debated by the researchers of this area. In order to do that, we will present a frame about some trends in the debate that has been done in Brazil, aiming to indicate some of the main paradigms which guided the different
\end{abstract}

\footnotetext{
* Doutor em Educação pela UNESP/Marília e Professor do Departamento de Didática e do Programa de Pós-graduação em Educação da Faculdade de Filosofia e Ciências UNESP/Marília. E-mail: gelamo@gmail.com

Pesquisa financiada pela FAPESP.
} 
approaches on the teaching of philosophy. We agree that this frame may not represent the whole discussion, but, in a way, it can be an index for us to understand what has been done in this debate.

KEY WORDS: Teaching of Philosophy. Brazilian thought. Education.

No Brasil a produção teórica sobre a temática do ensino da Filosofia é bem recente e ainda bastante restrita. ${ }^{1}$ Ao iniciarmos o levantamento bibliográfico sobre o assunto, notamos que a maior concentração das pesquisas está nas produções de pesquisadores ligados à Filosofia da educação, em sua maioria filósofos de formação, mas que atuam na área da educação. Apenas uma pequena parte daquilo que tivemos a oportunidade de analisar foi desenvolvida por filósofos vinculados aos cursos de Filosofia. Embora encontremos algumas publicações desses filósofos sobre o assunto, elas estão mais centradas nas questões político-educacionais concernentes à importância da Filosofia e do seu ensino na formação do cidadão, tema recorrente desde o final dos anos $1960 .^{2}$ A despeito da importância dada por vários filósofos ao ensino da filosofia, especialmente Kant e Hegel, ${ }^{3}$ quando não está diretamente vinculado à política educacional dos cursos de Filosofia, no que diz respeito especificamente

\footnotetext{
${ }^{1}$ Como bem observam Gallo e Kohan (2000), ao se referirem ao ensino secundário, "a bibliografia é parca, como bem sabe qualquer professor que, angustiado frente à esfinge da sala de aula, tenta buscar nos livros um alento para seu trabalho cotidiano, uma forma de melhor fundamentar sua prática docente. É certo que temos vários manuais para o ensino de filosofia nesse nível e mesmo alguns bons manuais. Mas a produção filosófica sobre o ensino da filosofia, entre nós, ainda é praticamente nula." (p. 7). Na nota de rodapé da mesma página fazem o seguinte esclarecimento "Isso se não considerarmos uma produção até razoável de dissertações de mestrado e teses de doutorado sobre o tema nesse período. Essas dissertações e teses, porém, raramente conseguem deixar as estantes das bibliotecas, chegando às mãos do professor de filosofia que está em sala de aula." Quando o assunto é o ensino da Filosofia nos cursos superiores a bibliografia ainda é mais restrita.

${ }^{2}$ A discussão sobre a importância da Filosofia se deve à retirada do ensino da Filosofia do Ensino Médio. Boa parte dos textos que foram publicados durante esse período procuram, de algum modo, uma sensibilização da importância desse saber para a formação humana.

${ }^{3}$ Cf. GELAMO (2007, 2008), HORN (2006), NOVELLI, (2005), PAGNI (2002) e SANTOS (1988)
} 
à formação dos seus estudantes, esse tema sempre é tratado como um problema de menor importância para a Filosofia, sendo essa tarefa deixada para os "educadores" - pedagogos e filósofos da educação. Talvez um dos motivos para tão poucas publicações seja justamente o fato de as questões do ensino da Filosofia serem entendidas como questões educacionais, o que possivelmente as distanciaria dos problemas filosóficos. Assim, a Filosofia poderia se ocupar de questões "mais importantes" e elevadas como a Metafísica, a teoria do conhecimento, a Ética, de forma geral e, principalmente, a História da Filosofia.

Uma das razões que podem explicar, mas não justificar, o pouco interesse sobre os problemas do ensino da Filosofia por parte dos filósofos pode estar localizada na história dos cursos de pós-graduação em Filosofia, entre os quais é raro encontrar um programa, área ou linha de pesquisa que se interesse pelo assunto ou que tenha como prioridade pensar o ensino da Filosofia. Corroborando nossa hipótese, outro indício dessa falta de interesse pode ser percebido quando percorremos a história da Associação Nacional de Pós-graduação em Filosofia (ANPOF), fundada em março de $1983 .{ }^{4}$ Notamos que, da sua fundação até 2006 , nunca houve na ANPOF um Grupo de Trabalho (GT) $)^{5}$ que tratasse especificamente do ensino da Filosofia e de seus problemas correlatos. Apenas em 2006 foi criado um espaço para a discussão sobre essa temática com a fundação

\footnotetext{
${ }^{4}$ Cf. página oficial da ANPOF disponível em: www.anpof.org.br.

${ }^{5}$ Os grupos de trabalho que compõem atualmente (2008) a ANPOF são os seguintes: Aristóteles; Benedictus de Spinoza; Ceticismo; Criticismo e Semântica; Dialética; Epistemologia Analítica; Estética; Estudos de Filosofia e História da Ciência; Ética; Ética e Cidadania; Ética e Filosofia Política; Ética e Política na Filosofia do Renascimento; Filosofar e Ensinar a Filosofar; Filosofia Antiga; Filosofia Contemporânea de Expressão Francesa; Filosofia da Ciência; Filosofia da História e Modernidade; Filosofia da Linguagem; Filosofia da Mente; Filosofia da Religião; Filosofia das Ciências Formais; Filosofia e Direito; Filosofia e Psicanálise; Filosofia Francesa Contemporânea; Filosofia na Idade Média; Filosofia Pós-Metafísica; Hegel; Heidegger; História da Filosofia da Natureza; História da Filosofia Medieval e a Recepção da Filosofia Antiga; História do Ceticismo; Kant; Levinas; Lógica; Lógica e Ontologia; Marx e a Tradição Dialética; Marxismo; Neoplatonismo; Nietzsche; Pensamento do século XVII; Platão e o Platonismo; Pragmatismo e Filosofia Americana; Rousseau e o Iluminismo; Schopenhauer; Teorias da Justiça; Wittgenstein.
} 
do GT, Filosofar e ensinar a filosofar. A própria escolha do nome foi significativa, uma vez que nomear o GT de "ensino da Filosofia" poderia causar uma confusão com algum tema da Filosofia da educação, ou alguma aproximação com problemas de aplicação pedagógica, que escapasse dos interesses da Filosofia, deixando que este assunto continuasse sendo pesquisado apenas nos programas de educação. ${ }^{6}$

Apesar do aceite da ANPOF em criar o referido GT, quando analisamos a constituição de seu Núcleo de sustentação, ${ }^{7}$ notamos que ele é composto majoritariamente por pesquisadores que estão vinculados às pós-graduações em educação ${ }^{8}$ e que desenvolvem pesquisas em Filosofia da Educação. Esse fato talvez possa evidenciar muito mais uma concessão por parte da associação dos filósofos envolvidos com a pós-graduação de que alguns pesquisadores da educação possam discutir os problemas

\footnotetext{
${ }^{6}$ Vale ressaltar que apenas o programa de pós-graduação em educação da Unicamp tem como linha de pesquisa o ensino da Filosofia. Criada em 2005, traz como pesquisadores Silvio Donizetti Gallo, René da Silveira Trentin, Lídia Maria Rodrigo e Roberto Goto.

${ }^{7}$ O Núcleo de sustentação do GT é composto por um coordenador que tenha título de doutor e por pelo menos mais cinco professores/pesquisadores com pesquisa na área e com reconhecida competência acadêmica. $<$ Cf. www.anpof.org.br $>$.

${ }^{8}$ Até o ano de 2008 o Núcleo de sustentação do GT tem como coordenador Gonzalo Armijos (UFG), vice-coordenador Walter Omar Kohan (UERJ), e como membros Elisete Tomazetti (UFSM), Filipe Ceppas (UGF), Gabriele Cornelli (UMESP), Geraldo Balduino Horn (UFPR), Humberto Guido (UFU), Junot Cornélio Matos (UNICAP), Leoni Maria Padilha Henning (UEL), Márcio Danelon (Unimep-UFU), Marcos Lorieri (PUC-SP), Maurício Rocha (UERJ), Paula Ramos (UNESP), Pedro Pagni (UNESP), Rosely Giordano (UFPA), Sérgio Sardi (PUC-RS), Sílvio Gallo (UNICAMP), Sônia Maria Ribeiro de Souza (Unisantos), Walter Matias Lima (UFAL). <cf. www.anpof.org.br>. Dos referidos pesquisadores, apenas Gonzalo Armijos, Maurício Rocha e Sérgio Sardi têm mestrado e doutorado em Filosofia, sendo que Rocha atua na pós-graduação em educação, Sardi não tem vínculo com a pós-graduação stricto sensu e apenas Palácio participa do curso de mestrado da Universidade Federal de Goiás, cujas linhas de pesquisa são: Ética e Filosofia Política Ontologia e Metafísica e Filosofia da Linguagem e Conhecimento, não havendo, no programa do qual participa nenhuma linha de pesquisa que abrigue a temática do GT. (Os dados foram pesquisados no Curriculum Lattes de cada pesquisador, disponível na Plataforma Lattes em 22 de novembro de 2007, In: lattes.cnpq.br).
} 
do ensino da Filosofia, do que um real interesse pelo assunto, uma vez que apenas um dos membros do GT desenvolve suas pesquisas em um programa de pós-graduação em Filosofia. ${ }^{9}$

Outro indício da falta de atenção dos filósofos aos problemas do ensino da Filosofia pode ser encontrado na pouca ocorrência de grupos de pesquisa inscritos no CNPq que se intitulam grupos de pesquisa em ensino da Filosofia ou que se dispõem a pesquisar o assunto. Existem, atualmente, 13 grupos inscritos no $\mathrm{CNPq}$, os quais nas linhas de pesquisa encontramos a ocorrência da preocupação com o tema ensino da Filosofia e, de forma mais geral, Filosofia e Educação. Dos referidos grupos, apenas 5 apontam como área predominante a Filosofia, ${ }^{10}$ enquanto que os outros 8 indicam a predominância na área de educação. $\mathrm{O}$ mesmo ocorre quando analisamos as produções de artigos sobre o assunto: a grande maioria é publicada em periódicos da área de educação ou em periódicos manifestamente interessados na interface Filosofia e Educação.

Talvez, ainda, parte desse problema esteja no modo como a aproximação entre a Filosofia e as questões do ensino ocorreu no Brasil. O

\footnotetext{
${ }^{9} \mathrm{Cf}$. Nota anterior.

${ }^{10}$ (1) Grupo (Gr): Educação e Filosofia - UNESP, líder (Li): Pedro Angelo Pagni, área predominante (AP): Educação; (2) - Gr: Filosofia, Cultura e Ensino Médio - UFSM, Li: Elisete Medianeira Tomazetti, AP: Educação; (3) - Gr: Filosofia e Educação - UPF, Li: Cláudio Almir Dalbosco, AP: Educação; (4) - Gr: Filosofia e Educação - Educogitans FURB, Li: Adolfo Ramos Lamar, AP: Educação; (5) Gr: Filosofia e Práxis Pedagógica - UNEMAT, Li: Aparecido de Assis, AP: Educação; (6) Gr: Filosofia, Educação e Subjetividade - UNB, Li: Walter Omar Kohan, AP: Educação; (7) Gr: Filosofia, Ética e Educação - UFPA, Li: Maria Neusa Monteiro, AP: Filosofia; (8) - Gr: Filosofia no Brasil e na América Latina: teoria, história e ensino - USP, Li: Antonio Joaquim Severino, AP: Educação, (9) - Gr: Grupo de Estudos e Pesquisas Filosofia para Crianças - UNESP, Li: Paula Ramos de Oliveira, AP: Filosofia; (10) Gr: Grupo de Estudos sobre Ensino de Filosofia - UNIMEP, Li: Marcio Aparecido Mariguela, AP: Filosofia; (11) Gr: Grupo de Pesquisa sobre Filosofia e Ensino de Filosofia - UFAL, Li: Walter Matias Lima, AP: Filosofia; (12) Gr: Núcleo de Estudos sobre o Ensino de Filosofia - NEFI - UFPI, Li: Helder Buenos Aires de Carvalho, AP: Filosofia; (13) Gr: PROPHIL: Pesquisas em Ensino do Filosofar - Educação para o Pensar - Filosofia para Crianças - Formação Humana - UFMT, Li: Peter Büttner, AP: Educação. (dados retirados do Diretório de Grupos de Pesquisa no Brasil - CNPq. Disponível em: <http://www.cnpq.br/gpesq/ apresentacao.htm>. Acesso em: 05 abril 2007).
} 
início do questionamento filosófico do ensino - e podemos dizer, também, do ensino da Filosofia - pode ser resgatado a partir dos textos de Anísio Teixeira, nos quais apresenta sua teoria educacional, entre os anos de $1930 \mathrm{e}$ 1934. ${ }^{11}$ Apesar de sua formação em Ciências Jurídicas, Teixeira envolveu-se com questões educacionais na Bahia e, posteriormente, no Rio de Janeiro e em Brasília. O ponto forte de sua inserção nas questões educacionais foi a participação ativa no Manifesto dos pioneiros da escola nova, em 1932. Durante esse período, Teixeira trouxe para a discussão educacional brasileira a perspectiva pragmatista de Dewey e Kilpatrick, ${ }^{12}$ com o intuito de fazer da educação e do ensino um problema filosófico. Em certo sentido, Teixeira inaugurou a Filosofia da Educação no Brasil e a preocupação com a aproximação entre as discussões educacionais e filosóficas.

Por esse motivo, durante longo período, a discussão sobre o ensino da Filosofia manteve-se submetida àquelas feitas pela Filosofia da Educação, a não ser por alguns artigos esparsos publicados por pesquisadores cujo vínculo era apenas com a Filosofia e não com a Filosofia da Educação. Podemos citar como exemplos dessas produções o artigo de Maugüé, O ensino da Filosofia: duas diretrizes, publicado na Revista Brasileira de Filosofia (1955), e A situação do ensino filosófico no Brasil, de João Cruz Costa (1959), professor catedrático do Departamento de Filosofia da Universidade de São Paulo (USP). Nesse sentido, até o final dos anos 1960, não houve grandes produções que tivessem como tema o ensino da Filosofia.

A preocupação dos filósofos estava centrada mais na constituição e sedimentação do curso de graduação em Filosofia da USP, criado em 1934, e na posterior criação do curso de pós-graduação, que se configurou como o principal responsável pela formação de filósofos no Brasil. Assim, a produção teórica do departamento da USP estava centrada, entre 1934 e 1957, na formação dos futuros professores do departamento, com o intuito de criar a base da Filosofia brasileira. Posteriormente, entre 1958 e 1968,

${ }^{11}$ Três textos são bastante ilustrativos sobre à presença do ensino da Filosofia no Brasil, especialmente no Ensino Médio, GALLINA (2000), HORN (2000) e FÁVERO, A. A. et al (2006).

${ }^{12}$ Sobre a influência de Anísio Teixeira na Filosofia da Educação brasileira, ver: Teixeira (1928, 1930a, 1930b, 1963, 1966, 1969, 1969a, 1969b e 2000) e Pagni (2000, 2000a, 2001 e 2008). 
a preocupação passou a ser a busca pela identidade e pela consolidação do curso de Filosofia. Isso pode ser encontrado na página institucional do Departamento de Filosofia da USP (2007) na internet, onde se lê:

O estilo de trabalho, consolidado no segundo período [1958 a 1969] que mencionamos acima, prescrevia para a graduação objetivos de formação técnica e crítica, centrado numa abordagem analítica da História da Filosofia, que visava dar ao aluno instrumentos teóricos para a compreensão das lógicas internas dos sistemas filosóficos. A preocupação dominante era o adestramento para a pesquisa de acordo com padrões herdados da historiografia francesa recente. Antes da Reforma Universitária tal trabalho podia ser desenvolvido de forma intensiva, uma vez que o currículo era constituído por um número relativamente reduzido de disciplinas, com pequena carga horária semanal e ministradas ao longo de um ano. Estas características conjugavam-se com exigências rigorosas no tocante à carga de leitura e trabalho aprofundado com os sistemas e autores tratados nas disciplinas. $^{13}$

Tendo em vista os objetivos acima enunciados, o que estava em voga no debate filosófico acerca do ensino da Filosofia no curso de Filosofia da USP era o adestramento dos alunos para a pesquisa filosófica e não a formação de filósofos que assumissem a carreira docente no segundo grau ou em cursos universitários, tendo como disciplinas Introdução à filosofia e Filosofia da educação. ${ }^{14}$ Assim, podemos dizer que a preocupação desses filósofos estava mais centrada na formação de pesquisadores da Filosofia do que na de professores.

13 Disponível em $<$ http://www.fflch.usp.br/df/site/departamento/historico.php $>$. Acesso em: 19 abril 2007.

${ }^{14}$ É possível encontrar algumas críticas ao modo como a Filosofia era - e ainda continua sendo - ensinada na USP. Exemplo disso é o livro de Renato Janine Ribeiro, A universidade e a vida atual (2003), no qual ele apresenta, dentre outros problemas da universidade brasileira, os limites do ensino estruturalista da filosofia. Não queremos entrar no mérito do debate sobre os prós e os contras do ensino estruturalista - ou estrutural - da Filosofia, amplamente utilizado no ensino da Filosofia da USP, pois, nosso objetivo não é esse. 
Apenas com uma intervenção externa - a Reforma Universitária no final da década de 60 - houve uma mudança nos objetivos do curso de Filosofia idealizado pelos fundadores da Faculdade de Filosofia da USP e por aqueles que os sucederam. No entanto, apenas nos últimos anos é que pode ser notada uma mudança significativa na constituição do curso:

É evidente que, nas condições atuais, o adestramento para a pesquisa não pode ser mantido, enquanto objetivo, com a predominância que possuía anteriormente. Este objetivo deve ser colocado em equilíbrio com dois outros, que são a formação profissional do docente de Segundo Grau, tendo em vista a reintrodução da disciplina no currículo, e a formação complementar de estudantes de outras áreas, formados ou não, que procuram o curso. Não consideramos, entretanto, que deva haver uma separação drástica entre preparar para a pesquisa e preparar para a docência no Segundo Grau: deve haver, pelo contrário, um equilíbrio entre as duas finalidades principais do curso, de modo a não excluir, discriminatoriamente, uma ou outra das opções do aluno ${ }^{15}$ (grifos no original).

No panorama geral do ensino da Filosofia, a reviravolta dessa situação se deu em outro contexto. Em 1961, a partir do decreto de lei $n$. 4.024/61, a Filosofia deixou de ser obrigatória no ensino. Com o Decreto de Lei de 869/69, regulamentado pelo Decreto 68.065/71, essas disciplinas foram substituídas pelas disciplinas de Educação Moral e Cívica e Ordem Social e Política Brasileira (OSPB), cujo objetivo era a defesa do princípio democrático, das tradições nacionais, da projeção de valores espirituais e éticos da nacionalidade por meio do fortalecimento da unidade nacional e do sentimento de solidariedade humana, do culto à pátria, das tradições e instituições, bem como do culto à obediência à lei, da fidelidade ao trabalho e da integração na comunidade (LEPRE, 2001). Assim, no lugar antes ocupado pelas disciplinas consideradas subversivas ao controle social, foi colocada uma disciplina que tinha como objetivo uma educação que preparasse os estudantes para o ingresso na sociedade, para o culto à pátria $\mathrm{e}$ para $\mathrm{a}$

15 Disponível em: $<$ http://www.fflch.usp.br/df/site/departamento/historico.php $>$. Acesso em: 19 abril 2007. 
obediência às leis estabelecidas, sem que para isso o aluno tivesse que fazer críticas ou compreender a sociedade. Porém, é em outro momento que a Filosofia sofre seu maior golpe, com a Lei n. 5.692/71, durante o período de ditadura militar (de 1964 a 1982), que fez com que a Filosofia e a sociologia fossem sumariamente retiradas do currículo escolar. Portanto, com essa retirada, foi despertado um debate que visava a uma conscientização social sobre a relevância da Filosofia na formação do cidadão crítico. ${ }^{16}$

A discussão sobre a importância do ensino da Filosofia foi sendo resgatada inicialmente às escuras, devido à repressão militar e, posteriormente, de maneira mais intensa, a partir da retomada da democracia nos anos 1980, com as manifestações em torno da volta da Filosofia aos currículos do Ensino Médio. Nesse contexto, os debates nos departamentos de Filosofia das universidades brasileiras desempenharam um importante papel, ainda que existissem discordâncias entre eles acerca dessas questões (GALLO, 2004).

Nesse sentido, a discussão sobre a importância do ensino da Filosofia no processo formativo tornou-se central no debate sobre o ensino da Filosofia, tendo como intuito recuperar o campo de intervenção social a ela reservado e que fora perdido. Segundo Appel,

Há muitos anos - desde a sua retirada, no início dos anos setenta, durante os chamados anos de chumbo do governo militar brasileiro - luta-se para reimplantar a filosofia no ensino médio. Bate-se contra o escândalo teórico e político da sua supressão e, ao mesmo tempo, constata-se que o ensino da filosofia se estende na medida em que a democracia avança. Compreende-se que não há propriamente ofício filosófico sem sujeitos democráticos e não há como atuar no campo político, consolidar a democracia, quando se perde o direito de pensar. (1999, p. 69).

O contexto histórico-social no qual viviam os filósofos brasileiros propiciava uma discussão que tinha como mote o convencimento e a explicitação para a sociedade em geral e para os responsáveis pela

${ }^{16}$ Uma análise sobre os motivos do afastamento da Filosofia do segundo grau pode ser encontrada no artigo de René José Trentin Silveira, "O afastamento e o retorno da filosofia ao segundo grau no período pós-64" (1994). 
educação, em particular da importância da recolocação da disciplina de Filosofia no Ensino Médio e da urgência em se efetivar isso. Assim, quase toda a discussão sobre o ensino da Filosofia firmou-se no debate sobre sua importância no ensino médio. ${ }^{17}$

A partir de 2000, no entanto, a expansão outrora responsável por difundir a Filosofia como disciplina nos cursos de graduação acabou por contribuir para que perdesse espaço em tais cursos. Nesse sentido, as faculdades e institutos de ensino superior vêm gradativamente retirando a disciplina de Introdução à Filosofia, de Filosofia da Educação e de Filosofia e Ética Fundamental de seus currículos escolares. A justificativa para isso recai no argumento de que há uma exigência de apressamento na formação do aluno universitário pela demanda do mercado e que, por isso, disciplinas que não contribuam diretamente com a formação profissional precisam ser eliminadas do currículo. Outro argumento que ampara a supressão da Filosofia nesses cursos é a necessidade de que as disciplinas menos necessárias dêem lugar àquelas de "fundamental importância" à formação técnica. A título de exemplo, os cursos de pedagogia que tinham suas disciplinas divididas ao longo de quatro anos, atualmente são realizados em apenas três anos em boa parte das faculdades, especialmente as privadas. Poderíamos imputar a razão disso simultaneamente à pressa das instituições privadas em formar os alunos para obter maior lucro com sua formação e à pressa dos próprios alunos para entrar no mercado de trabalho o mais rapidamente possível. No entanto, notamos que mesmo as instituições de ensino público seguem um caminho muito parecido, descartando de seus currículos a disciplina de Filosofia ${ }^{18} \mathrm{e}$, em alguns casos, inclusive a de Filosofia da Educação.

${ }^{17}$ Todo esse debate sobre o ensino da Filosofia no Ensino Médio foi politicamente muito importante, porém, nesse mesmo contexto, o debate necessário de ser realizado sobre o ensino de Filosofia nos curso superiores foi prejudicada (especialmente aqueles que não tinham como objetivo a formação filosófica Bacharelados e Licenciaturas em Filosofia). A consequência disso foi a gradual retirada do ensino da Filosofia na da formação universitária, principal espaço que ocupou quando do declínio de sua ação no Ensino Médio e, principalmente, no final da década de 1980, com a grande expansão e abertura de cursos superiores.

${ }_{18}$ Para nos determos a apenas um exemplo desse fato, podemos fazer referência à recente retirada da disciplina de Introdução à Filosofia do curso de Pedagogia da Unesp de Marília em 2006, sob alegação da necessidade de criar espaço para 


\section{A esse respeito, Gallo observa que}

Na universidade brasileira hoje, não vemos a presença da filosofia nos currículos dos cursos, a não ser no caso de instituições confessionais, que entendem que conhecimentos de filosofia são necessários para a realização de seu projeto pedagógico.

Nas universidades públicas, a presença da filosofia nos cursos dá-se apenas quando é diretamente relacionada com aquela carreira. (2007, s/p).

Nesse sentido, podemos inferir que restou à Filosofia ser uma disciplina de caráter instrumental ou interdisciplinar, como alguns preferem intitulá-la, cabendo a ela ocupar o espaço de transversalidade nos currículos. Assim, o ensino da Filosofia deixou de ser um saber que precisasse de alguém especializado para ministrá-lo. Isso fez com que sofresse uma simplificação excessiva, passasse a ser um conhecimento comum - senso comum - e, desta forma, todos puderam se sentir "capazes" de ensinar a Filosofia transversalmente. Esse modo de tratar o ensino da Filosofia encontra respaldo na Lei n. 9.394/96, que, apesar de trazer a possibilidade do retorno da Filosofia para o Ensino Médio e de assumir a sua importância, reserva a ela um lugar de pura aparência, principalmente em um tema caro à Filosofia que é a ética.

Dadas as mazelas pelas quais a Filosofia passou, nas últimas décadas, a preocupação dos estudiosos acerca do ensino da Filosofia localizouse em um aspecto que precisava ser evidenciado: o convencimento da importância da Filosofia na formação dos alunos nos Ensinos Fundamental, Médio, Superior e, até mesmo, no ensino da Filosofia para crianças, com o objetivo de marcar o seu lugar na formação crítica do sujeito.

Nos anos 1990, notamos que houve uma continuidade na discussão sobre a importância da existência do filósofo na sociedade, reiterando a tendência em se marcar posição quanto à necessidade da Filosofia para a formação do cidadão crítico. A esse respeito podemos fazer referência ao livro de Arantes et al, A filosofia e seu ensino, de $1991,{ }^{19}$ o qual reuniu

\footnotetext{
"disciplinas imprescindíveis" à formação dos futuros pedagogos.

19 Tendo em vista que utilizamos a segunda edição, de 1996, passaremos a fazer
} 
vários filósofos que, naquele momento, estavam preocupados em pensar o ensino da Filosofia como uma disciplina que poderia contribuir para se pensar a dimensão social do homem, hipótese desenvolvida por Franklin Leopoldo e Silva no capítulo intitulado: A função social do filósofo (1996).

Nos anos 2000, a temática manteve-se e, de certo modo, intensificou-se, principalmente a partir da aprovação pelo congresso nacional e respectivo veto do presidente da República em 2001 do Projeto de Lei n. 3178/97 que versava sobre a obrigatoriedade do ensino da Filosofia e Sociologia no Ensino Médio. Devido a esse contratempo, as discussões sobre a importância do ensino da Filosofia e das condições para sua implantação tomaram uma força muito maior no cenário nacional, uma vez que o motivo do veto foi a falta de professores para assumir as respectivas aulas. Tomazetti destaca que,

[...] apesar da derrota, instaurou-se positivamente um processo de reflexão sobre o ensino da filosofia, suas exigências, dificuldades, forma e conteúdo. E mais, dentro de um contexto nacional de discussões e de novas políticas para a formação de professores, passou-se a discutir a formação inicial do professor de Filosofia dentro de um curso que, mesmo sendo de licenciatura, muitas vezes enfatiza a formação para a pesquisa, em detrimento da preparação para a docência. $(2002, \mathrm{~s} / \mathrm{p})$

Em consonância com o debate público que ocorria no Brasil, surgiram vários encontros que visavam ampliar ainda mais o debate público sobre o assunto: I Congresso internacional de filosofia com crianças e jovens (1999) em Brasília; Congresso brasileiro de professores de filosofia (2000) em Piracicaba; Simpósio sobre o ensino da filosofia da região sudeste (2002) em Piracicaba; Fórum sul de ensino da filosofia ${ }^{20}$

referência a esse livro como sendo de 1996.

${ }^{20}$ O Fórum Sul de Ensino de Filosofia, já em sua $8^{\mathrm{a}}$ edição, é resultado da união de vários cursos de Filosofia do sul do Brasil que se preocupam em debater o ensino da Filosofia. Os encontros tiveram início em 2001 com o tema "Um olhar sobre o ensino da filosofia" e, a partir de então, foram realizados anualmente e discutiram os seguintes temas: "Filosofia e ensino em debate" (2002); "Filosofia e Ensino: possibilidades e desafios" (2003); "Filosofia e ensino: um diálogo transdisciplinar" (2004); "Filosofia e 
(de 2001 a 2008) em Passo Fundo, Ijuí, Curitiba, São Leopoldo, Santa Maria e Londrina; Fórum centro-oeste sobre ensino e pesquisa em filosofia (2001, 2002, 2003, 2004), em Brasília, Goiânia e Palmas; Fórum norte de ensino da filosofia (2004), em Belém do Pará. Esses Fóruns e Simpósios têm se preocupado em trazer à tona o debate, não só do ensino da Filosofia no segundo grau ou na universidade, ${ }^{21}$ mas também a problemática do ensinar a Filosofia para estudantes do curso de Filosofia. Nesse sentido, a ressonância da preocupação dos estudos realizados nas décadas anteriores pode ser encontrada no empenho dos organizadores desses eventos em dar continuidade à discussão sobre a temática do ensino da Filosofia.

Notamos que toda essa discussão tem surtido efeito, uma vez que a Filosofia tem ganhado visibilidade e a procura por cursos de licenciatura nessa área tem aumentado significativamente. Em diversos estados do Brasil o ensino dessa disciplina tornou-se obrigatório no Ensino Médio, embora ainda existam diversas discordâncias sobre a implantação das resoluções e sobre os jogos políticos dos Conselhos Estaduais e Federais de Educação a respeito da determinação do Conselho Nacional. Outro campo no qual a Filosofia tem ganhado espaço é a participação nos exames vestibulares, ${ }^{22}$ por meio da elaboração tanto de questões que tratam especificamente de conhecimentos filosóficos quanto das que utilizam a Filosofia como um saber "transversal", visando à compreensão filosófica de certas questões.

Alguns debates, ainda que tenham tomado menores proporções, podem ser resgatados por seu forte viés metodológico, ou seja, por darem ênfase à compreensão de uma metodologia do ensino da Filosofia e à confecção de manuais ou de livros didáticos. Nesse sentido, alguns estudiosos dedicam-se a pensar o ensino da Filosofia como um resgate de temas que sejam importantes para o enriquecimento dos conhecimentos

Ensino: a filosofia na escola" (2005); "Filosofia na Universidade" (2006); "Filosofia e sociedade" (2007); Filosofia, formação docente e cidadania (2008).

${ }^{21}$ Estamos nos referindo aos cursos que têm em sua grade curricular as disciplinas de Filosofia, Filosofia da Educação, Filosofia e Ética etc.

${ }^{22}$ Isso tem ocorrido apesar de toda a problematização em relação aos males que a implantação nos vestibulares pode causar à Filosofia. Um breve relato sobre a iniciativa feita pela UFU pode ser encontrado no artigo escrito por Guido (2000), no livro Filosofia no Ensino Médio. 
dos alunos. Isso está sendo debatido mais detidamente desde a década de 80 pela comunidade filosófica brasileira, principalmente pelos filósofos da educação, tendo por objetivos compreender o problema e propor encaminhamentos para o ensino da Filosofia. De acordo com Gallina,

Na década de 80 ocorreram intensos debates sobre o ensino da filosofia, os quais são importantes na medida em que nos mostram não somente o que pensam os filósofos brasileiros sobre a filosofia e o seu ensino, mas também a sua influência às futuras gerações de professores de filosofia. (2004, s/p).

Não obstante, a discussão desse período foi marcada, segundo Gallina (2004), pela discussão acerca dos temas e conteúdos a serem ensinados. Em 1989 e 1994 surgiram dois manuais que traziam vários temas e conteúdos que perpassavam algumas correntes filosóficas, objetivando auxiliar o professor em suas atividades pedagógicas: Filosofando (ARANHA, 1989) e Convite à filosofia (CHAUI, 1994). O primeiro deles traz em sua apresentação um viés marxista e o segundo, por meio de uma abordagem mais histórico-temática dos temas e conteúdos filosóficos, reconstrói historicamente os temas que foram objeto da problematização filosófica, apresentando o modo como vários filósofos os perspectivaram. Esses manuais foram largamente utilizados pelos professores de Filosofia, pois, de certo modo, traziam de forma sintetizada vários temas e autores que poderiam ser trabalhados por eles. ${ }^{23}$

Diante da explanação acerca do modo como o ensino da Filosofia está sendo tratado no Brasil, podemos indicar que as questões que o envolvem são debatidas no contexto atual. Porém essas questões muitas vezes se concentram em três preocupações que norteiam as pesquisas: (1) o entendimento da importância do ensino da Filosofia para a sociedade, para a cultura e para a

\footnotetext{
${ }^{23}$ Esses manuais de Filosofia, segundo as autoras, foram elaborados com o intuito de fornecer um material para os estudantes de Filosofia do Ensino Médio. No entanto, é o material mais utilizado nos cursos universitários. O livro Convite à filosofia, no ano de 2003, já estava na sua $13^{\text {a }}$ edição. O mesmo ocorreu com o livro Filosofando, que, em 2003, estava na $3^{\mathrm{a}}$ edição, sem computar, neste trabalho, as várias reimpressões feitas nesse período.
} 
formação crítica do homem; (2) a reflexão sobre os temas e conteúdos a serem ensinados e sobre o currículo; e (3) a busca do entendimento metodológico do ensino da Filosofia. Notamos nesse contexto uma escassez de pesquisas que problematizem a relação do filósofo com a tarefa que lhe é confiada: ser professor de Filosofia, ${ }^{24}$ a não ser quando o entendimento do ser professor de Filosofia está vinculado à escolha dos métodos e conteúdos a serem ensinados e ao entendimento da importância do ensino da Filosofia. Talvez isso tenha reafirmado um posicionamento pedagógico a partir de uma problematização educacional dos métodos e conteúdos e de um posicionamento filosófico sobre a importância desse ensino.

Não queremos neste artigo negar o justo posicionamento afirmando que todo o debate que existiu no Brasil sobre o ensino da Filosofia tenha sido importante e necessário, ao contrário, concordamos que, se ele não tivesse existido, a situação do ensino da Filosofia estaria muito pior. Todo esse debate fez e continua fazendo parte disso que podemos chamar de momento histórico do ensino da Filosofia no Brasil. Nossa intenção foi delinear e, de algum modo, destacar como o debate circulou ao redor dessas questões.

\section{Referências}

ANPOF. Associação nacional de Pós-graduação em Filosofia. Disponível em: <www.anpof.org.br>. Acesso em: 15 mar 2006.

APPEL, E. J. Filosofia nos Vestibulares e no Ensino Médio. Cadernos Pet-Filosofia. n. 2, 1999. Disponível em: < http://www.filosofia.ufpr.br/pet/ cadernos/numero2/emmanuel.pdf $>$. Acesso em: 01 abr 2007.

ARANHA, M. L. A. MARTINS, M. H. P. Filosofando: introdução à filosofia. São Paulo: Moderna, 1989.

ARANTES, P. et al. A filosofia e seu ensino. Petrópolis, RJ: Vozes; São Paulo: Educ, 1996. 2. ed.

\footnotetext{
${ }^{24}$ Alguns autores procuram fazer essa problematização a partir de um deslocamento na tematização do ensino da Filosofia. Dentre eles, podemos destacar as pesquisas dos integrantes dos grupos de pesquisa coordenados por Silvio Gallo e Walter Kohan.
} 
BRASIL. Decreto de lei no 4.024, de dezembro de 1961. Disponível em: $<$ http://www.planalto.gov.br/ccivil_03/LEIS/L4024.htm >. Acesso em: $10 \mathrm{mar}$ 2006.

BRASIL. Decreto de lei no 68.065, 14 de janeiro de 1971. Disponível em: $<$ http://www.histedbr.fae.unicamp.br/navegando/fontes_escritas/7_Gov_Militar/ artigo_003.html >. Acesso em: 21 mar 2006.

BRASIL. Decreto de lei no 5.692,11 de agosto de 1971. Disponível em: $<$ http://www.planalto.gov.br/ccivil_03/LEIS/L5692.htm>. Acesso em: $21 \mathrm{mar}$ 2006.

BRASIL. Decreto de lei no 9.394, dezembro 1996. Disponível em: $<\mathrm{http}: / /$ www.consumidorbrasil.com.br/consumidorbrasil/textos/legislacao/19394.htm>. Acesso em: 21 mar 2006.

BRASIL. Projeto de Lei $n$. 3178/97.

BRASIL. Decreto de lei no 11.684, 2008. Disponível em: <http://www. planalto.gov.br/ccivil_03/_Ato2007-2010/2008/Lei/L11684.htm>. Acesso em: 24 nov 2008.

COSTA, J. C. A situação do ensino filosófico no Brasil. In:

Panorama da História da Filosofia no Brasil. São Paulo: Cultrix, 1959.

CNPQ. Curriculum lattes. In: CNPq. Disponível em: <lattes.cnpq.br>. Acesso em 20 jan 2006.

CNPQ. Página oficial do CNPq. In: $C N P q$. Disponível em: <www.cnpq.br>. Acesso em 20 jan 2006.

CNPQ. Página oficial do Diretório dos grupos de pesquisa no Brasil. Disponível em: <http://www.cnpq.br/gpesq/apresentacao.htm>. Acesso em: 05 abr 2007.

CHAUÍ, M. O que é ser educador hoje? Da arte à ciência: a morte do educador. In: BRANDÃO, C. At all. O educador hoje. 10. ed. Rio de Janeiro: Graal, 1992. p. 51-70.

FÁVERO, A. A. et al. O ensino da filosofia no Brasil: um mapa das condições atuais. Cad. CEDES., Campinas, 2004. v. 24, n. 64. Disponível em: <http://www.scielo.br/scielo.php?script=sci arttext\&pid $=$ S0101-32622004000300002\&lng=pt\&nrm $=$ iso $>$. 
Acesso em: 01 Dez 2006.

GALLINA, S. F. S. A disciplina de filosofia e o ensino Médio. In: GALLO, S.; KOHAN, W. Filosofia no ensino médio. Petrópolis: Vozes, 2000. p. 34-46.

GALLINA, S. O ensino da filosofia e a criação de conceitos. In: $\mathrm{Cad}$. CEDES., Campinas, 2004. v. 24, n. 64.

GALLO, S.; KOHAN, W. Apresentação. In: Filosofia no ensino médio. Petrópolis: Vozes, 2000. p. 7-10.

GALLO, S. Educação, Ideologia e a construção do sujeito. Disponível em: <www.educacaoonline.pro.br/educacao_ideologia.asp?f_id_artigo $=183>$. Acesso em: 10 nov 2004.

GALLO, S. A função da filosofia na escola e seu caráter interdisciplinar. In: Centro de Referência em Educação Mário Covas. Disponível em: <www. crmariocovas.sp.gov.br/pdf/ccs/pebII/silvio_gallo.pdf $>$. Acesso em: 03 abr 2007.

GELAMO, R. P. Re-visitando as reflexões kantianas sobre a importância da educação, do ensino e do filosofar. In: Itinerários de filosofia da Educação. Portugal: Porto, 2007. n. 2. p. 77-91.

GELAMO, R. P. O ensino da filosofia e o papel do professor filósofo em Hegel. In: Trans/Form/Ação. Marília, 2008. v.31, n. 2.

GUIDO. H. A. O. A filosofia no ensino Médio: uma disciplina necessária. In: GALLO, S.; KOHAN, W. Filosofia no ensino médio. Petrópolis: Vozes, 2000. p. 81-93.

HORN, G. B. Do ensino da filosofia à filosofia do ensino: contraposições entre Kant e Hegel. In: REUNIÃO ANUAL DA ANPED, 26, 2003. Poços de Caldas. Anais eletrônicos... Poços de Caldas: ANPED. Disponível em: <http://www.anped.org.br/reunioes/26/trabalhos/geraldobalduinohorn.rtf $>$. Acesso em: $10 \mathrm{dez} 2006$.

HORN, G. B. A presença da filosofia no currículo do Ensino Médio brasileiro: uma perspectiva histórica. In: GALLO, S.; KOHAN, W. Filosofia no ensino médio. Petrópolis: Vozes, 2000. p. 17-33.

LEPRE, R. M. A indisciplina na escola e os estágios de desenvolvimento moral na teoria de Jean Piaget. 182 p. Dissertação (Mestrado em Educação) 
- Universidade Estadual Paulista “Júlio de Mesquita Filho". arília, 2001. MAUGÜÉ, J. O ensino da filosofia: suas diretrizes. In: Revista Brasileira de filosofia. São Paulo, 1955. v.5, fasc. 4, n. 20. p. 642-649.

NOVELLI, P. G. A. O ensino da filosofia segundo Hegel: contribuições para a atualidade. In: Trans/Form/Ação. Marília, 2005. v. 28, n. 2. p. 129-138.

PAGNI, P. A. A filosofia da educação de Anísio Teixeira: da doutrina política à teoria da investigação. In: Especiaria: Revista da UESC. Ilhéus, jan/dez 2000. ano III, n. 5 e 6. p. 33-58.

PAGNI, P. A. Do "Manifesto de 1932" à construção de um saber pedagógico: ensaiando um diálogo entre Fernando de Azevedo e Anísio Teixeira. Ijuí: Editora Unijuí, 2000a.

PAGNI, P. A. A constituição da filosofia da educação de Anísio Teixeira (1930-1934): entre a doutrina filosófica e a crítica pedagógica. In: MONARCHA, C. (org.) Anísio Teixeira: a obra de uma vida. Rio de Janeiro: DP\&A Editora, 2001. p. 153-192.

PAGNI, P. A. O ensino da filosofia nas obras de Kant, de Hegel e de Nietzsche: uma breve análise histórico-filosófica. In: Reflexão e ação. Revista do departamento de educação. UNISC: Santa Cruz do Sul, jul./ dez. 2002. v.10, n.2. p. 111-135.

PAGNI, P. A. Anísio Teixeira. Experiência reflexiva e projeto democrático: a atualidade de uma filosofia da educação. Petrópolis: Vozes, 2008.

SANTOS, L. R. Kant e o ensino da Filosofia. Filosofia - Sociedade Portuguesa de Filosofia. Lisboa. primavera 1988. vol. II, n. 1/2.

SILVEIRA, R. J. T. O afastamento e o retorno da filosofia ao segundo grau no período pós-64. Pró-posições. Campinas, 15 nov 1994. vol.5. n. 3.

TEIXEIRA, A. Aspectos Americanos da Educação. Salvador: Tipographia S. Francisco, 1928.

TEIXEIRA, A. A Pedagogia de Dewey (Esboço da theoria de educação de John Dewey) In: DEWEY, J. Vida e Educação. Trad. Anísio Teixeira. São Paulo: Melhoramentos, 1930a.

TEIXEIRA, A. Por que "escola nova"? Bahia: Livr. e Typ. do Commercio, 
1930b. Boletim n.1, Associação Bahiana de Educação.

TEIXEIRA, A. Mestres de amanhã. Revista Brasileira de Estudos Pedagógicos. Rio de Janeiro, out/dez 1963. v.40, n.92. p.10-19.

TEIXEIRA, A. O problema de formação do magistério. Revista Brasileira de Estudos Pedagógicos. Brasília, out/dez 1966. v.46, n.104. p. 278-287.

TEIXEIRA, A. A Ciência e a arte de educar. In : Revista Brasileira de Estudos Pedagógicos. Educação e o Mundo Moderno. São Paulo: Companhia editora Nacional, 1969. p. 25-35.

TEIXEIRA, A. Democracia e educação. Revista Brasileira de Estudos Pedagógicos. Educação e o Mundo Moderno. São Paulo: Companhia editora Nacional, 1969'. p. 205-221.

TEIXEIRA, A. Filosofia e educação. Revista Brasileira de Estudos Pedagógicos. Educação e o Mundo Moderno. São Paulo: Companhia Editora Nacional, 1969b. p. 9-25.

TEIXEIRA, A. Pequena introdução à Filosofia da Educação: a escola progressiva ou a transformação da escola. 6. ed. Rio de Janeiro: Editora DP\&A, 2000. [Edição Comemorativa 100 anos]

TOMAZZETI, E. Filosofia no ensino médio e seu professor: algumas reflexões. Revista do centro de educação, Santa Maria. v. 27, n. 2, p. 6975, 2002. Disponível em: <http://coralx.ufsm.br/revce/>. Acesso em: 04 abr 2007.

USP. Página oficial do curso de filosofia da USP. Disponível em: $<\mathrm{http}: / /$ www.fflch.usp.br/df/site/departamento/historico.php>. Acesso em: 19 abr 2007. 
